IRA-International Journal of Education \& Multidisciplinary Studies

ISSN 2455-2526; Vol.08, Issue 02 (August 2017)

Pg. no. 164-174

Institute of Research Advances

http://research-advances.org/index.php/IJEMS

\title{
Therapeutic Breathing Techniques and Disparity across Student Performance in English and Mathematics
}

\author{
Abha Gupta ${ }^{1}$ Shana Pribesh $^{2}$ and Norou Diawara ${ }^{3}$ \\ ${ }^{1}$ Department of Teaching and Learning, Old Dominion University, Norfolk, Virginia 23529, USA \\ ${ }^{2}$ Department of Educational Foundations and Leadership, Old Dominion University, Norfolk, Virginia \\ 23529, USA \\ ${ }^{3}$ Mathematics and Statistics Department, Old Dominion University, Norfolk, Virginia 23529, USA
}

Type of Review: Peer Reviewed.

DOI: http://dx.doi.org/10.21013/jems.v8.n2.p2

\section{How to cite this paper:}

Gupta, A., Pribesh, S., Diawara, N. (2017). Therapeutic Breathing Techniques and Disparity across Student Performance in English and Mathematics. IRA International Journal of Education and Multidisciplinary Studies (ISSN 2455-2526), 8(2), 164-174. doi: http://dx.doi.org/10.21013/jems.v8.n2.p2

(C) Institute of Research Advances.

\section{(cc) Br-no}

This work is licensed under a Creative Commons Attribution-Non Commercial 4.0 International License subject to proper citation to the publication source of the work.

Disclaimer: The scholarly papers as reviewed and published by the Institute of Research Advances (IRA) are the views and opinions of their respective authors and are not the views or opinions of the IRA. The IRA disclaims of any harm or loss caused due to the published content to any party.

Institute of Research Advances is an institutional publisher member of Publishers Inter Linking Association Inc. (PILA-CrossRef), USA. The institute is an institutional signatory to the Budapest Open Access Initiative, Hungary advocating the open access of scientific and scholarly knowledge. The Institute is a registered content provider under Open Access Initiative Protocol for Metadata Harvesting (OAI-PMH).

The journal is indexed \& included in WorldCat Discovery Service (USA), CrossRef Metadata Search (USA), WorldCat (USA), OCLC (USA), Open J-Gate (India), EZB (Germany) Scilit (Switzerland), Airiti (China), Bielefeld Academic Search Engine (BASE) of Bielefeld University, Germany, PKP Index of Simon Fraser University, Canada. 


\begin{abstract}
This paper explores possible correlation between Therapeutic Breathing Techniques (TBT) and improved academic performance of low achieving students in elementary school. The intervention consisted of daily breathing exercises combining two forms of TBT, namely, deep breathing and alternate nostril breathing. A semester-long quantitative study with85 second graders was conducted to investigate the impact of above intervention on English and mathematics scores. Following one semester of intervention, the gaps between the low and high achievers had narrowed and small but significant gain-scores were found for the low achievers who had practiced TBT. In contrast, in first and third grades, where neither low achievers nor high achievers received the treatment, the gap between the low and high achievers widened slightly. The findings indicate the need to further investigate the potential merit of therapeutic breathing exercises as a low-cost intervention strategy for improving school performance and addressing achievement gaps, especially in mathematics.
\end{abstract}

KEYWORDS: Therapeutic breathing techniques, alternative intervention, yoga, English, mathematics, achievement gap

\title{
1. THERAPEUTIC BREATHING TECHNIQUES AND THE ACHIEVEMENT GAP
}

The concept of therapeutic breathing techniques (TBT) and mindfulness has long been practiced in Eastern spiritual traditions of yoga for personal improvement. Educators and educational institutions have recently begun to explore their secular applications in learning environments (Larson, et al 2010, Telles, et al 2007, Peck, et al 2005,Stueck, et al 2005).Over the past decade, a body of literature has emerged supporting the efficacy of mindfulness-based treatment approaches (Leland, 2015, Willis, 2014, Williamson, 2012, Napper-Owen, 2006). Mindfulness often refers to specific practices emphasizing single-pointed concentration and attention on the present moment that is characterized by nonjudgmental observation of experience (Broderick \& Jennings, 2012). For the purpose of the present study, we make a distinction between mindfulness and TBT as TBT underscores breath modulation with therapeutic benefits as the principal element of the intervention. Central to therapeutic breathing techniques is the method of rhythmic attentive breathing. Therapeutic breathing is a largely under-explored aspect of research in education. Given the promise of yoga, TBT has become a focus of considerable research devoted to its health outcomes (Grossman, et al., 2004). In a 2005 meta-review, Richard Brown, MD, and Patricia Gerbarg, MD, reported that yogic deep breathing was extremely effective in addressing depression, anxiety, and stress related disorders. In the present study, we examine the potential relationship between TBT and the disparity between academic performances of low achieving students and high achieving students.

In the yogic tradition, breath control exercises emphasize slow and deep breathing. Deep breathing has been shown to increase the body's overall circulation by releasing tension and increasing levels of blood and oxygen throughout the entire body (Brosnan, 1982; Lalvani, 1999). The central autonomic nervous system, which is the body's regulatory system for involuntary activity, such as heartbeat and respiration, responds favorably to increased levels of oxygen. The central nervous system is divided into two subsystems known as the sympathetic and parasympathetic nervous systems, respectively. Deep breathing exercises influence both of these subsystems by deactivating the sympathetic system and activating the parasympathetic system (Carlson 1998; Seamon \& Kenrick 1994). The result is a sense of calmness, emotional balance, and increased concentration (Brosnan, 1982). Breathing exercises train the youths to center and calm themselves (Mendelson, et al 2010).

The two breathing techniques of deep breathing and alternate nostril breathing purport to provide therapeutic benefits for memory and brain cells (Telles, et al 2007). Deep breathing exercise stimulates slow, deep, and rhythmic breathing, which results in increasing the amount of oxygen in the blood stream, thereby improving blood circulation. Well-oxygenated and well-circulated blood invigorates all body cells, including the brain cells. The second technique, alternate nostril breathing, activates balance between the dominances of the brain's left and right hemispheres. The nasal passages are cross-connected with the two hemispheres of the brain. Therefore, alternate nostril breathing not only improves the balance between the right and left brains, but also calms the mind by optimizing the analytical leftbrain and the creative right brain (Telles et al. 2007). 
Calm breathing is thought to help focus the mind and regulate the autonomic nervous system, which results in mental relaxation. Mind-body techniques facilitate attention skills, which help with the performance in school. Improved coping skills can guide feelings of discomfort in stressful situations. In a study that involved teaching relaxation techniques to fifty children with behavioral problems found reduced symptoms of inattention and hyperactivity when compared to the control group on the Parent Child Behavior Checklist (Goldbeck and Schmid, 2003). More relaxed mind promotes self-control, attention and concentration, selfefficacy, body awareness, and stress reduction (Nardo \& Reynolds, 2002).

Yoga programs in elementary schools that incorporate balancing, bending, and stretching exercises have been a growing area of research (Berger, Silver, \& Stein, 2009; Clance, Mitchell, \& Engel man, 1980), but few have specifically examined the effect of breathing exercises on academic performance. While there is some empirical evidence to support the efficacy of breathing exercises for behavior modification (Peck, et al. 2005, Steiner, et al. 2013), there is an absence of research aboutthe effect of breathing exercises on direct measures of educational achievement. One exception is Gupta et al. (2014), who examined the connection between therapeutic breathing exercises and educational outcomes for third graders. Statistically controlling for academic differences that preceded the intervention, the researchers found that students who engaged in TBT breathing scored higher on the end of year English test than those who did not engage in the intervention. This study suggested that $T B T$ holds promise for improving educational outcomes.

The students in the Gupta et al. (2014) study were randomly assigned to the treatment and control groups. Thus, both groups largely started at the same place in terms of pretest group means. However, that studydid not examine how the therapeutic breathing exercises might address the most at-risk, school-aged population, namely, the low achievers. The gap between low and high achieving students often predates the start of elementary school (Jencks and Phillips, 1998). On average, the gap persists from one grade level to the next (Chatterji, M., 2006). The cumulative effect over several academic years leads to a widening of the gap between the low achievers and the high achievers. Typically, school-based problems such as academic underachievement are often related to impulsivity, inattention, and hyperactivity in the classroom (Faraone et al., 1993). Low achievers in fifth grade are highly more likely to drop out of school and, over the course of their lifetimes, they earn just a fraction of the earnings of students with a high school or a post-secondary degree. Often termed the opportunity gap, early achievement gaps often translate into wider class and income gaps later in life.

Interventions designed to close the achievement gap often involve remediation and expensive summer programs. One-on-one tutoring has shown some promise (Gupta, et al, 2014) but is onerous to implement from the standpoint of both effectiveness and efficiency. Tutors must be located, vetted, and trained, which is very expensive, and out of the reach of many school divisions. Curricular interventions targeting low achievers are not only expensive but have also not proven to be successful. Summer programs are poorly attended, expensive, and often not very effective. Even large-scale interventions such as closing and reconstituting the schools designed to redistribute low achieving students have been largely ineffective.

The use of therapeutic breathing exercises offers a potentially cost effective intervention that students can practice at school and/or at home. As mentioned in the description of the intervention framework below, training for the involved professionals can be provided via online resources through video links, without accruing any recurring cost. There is also no additional cost for materials, printing, or travel.

\section{METHODOLOGY}

\subsection{Research Question}

The purpose of this study is to explore the relationship, if any, between therapeutic breathing exercises and educational achievement, with an emphasis on low achieving students as compared to the high achievers. To that end, we examine the following research question: To what extent do low and high achievers' scores in English and mathematics converge after a TBT based intervention?

\subsection{Design}

The relationship between therapeutic breathing exercises and the educational achievements of low and high achievers was explored using a quasi-experimental design. Specifically, we used a non-random pretest/posttest 
with control group design to examine the gain scores of second grade students. The intact classrooms were intentionally different from one another - one contained low achieving students and the other was made up of high achieving students. Low-achieving students received intervention during the school assembly time in the morning while the comparison group students were in the assembly. The school assembly consisted of singing the national anthem, followed by thought-of-the-day exercise and an inspiring account of a leader. Thus, the treatment group did not miss any instructional time. The low achieving classroom received the treatment in the form of therapeutic breathing exercises. In the present work, we mimic a regression discontinuity design by examining the achievement gaps of the same students when they were in first grade as well as students in the third grade. We expected that, if the therapeutic breathing exercises have a positive impact on the academic performance of low achievers, then the current low and high achievers in first and third grade, where no intervention occurred, will maintain the achievement gap while in the second grade, the intervention will shrink the achievement gap.

\subsection{Participants}

A majority of the participants lived in suburban or rural parts of the city Modi Nagar in northern India with a population of app 130,325 people. The students who participated in this study attended a suburban, private, English medium, junior middle school (KG-8) near New Delhi, India. The school has nearly 1100 students, 35 teachers, and 22 classrooms. The school had two sections at each grade level, with approximately50 students in each section. The average class size was 50-60 students. Students who attended this school came from modest backgrounds; the average family income was about $\$ 100$ per month. Children's primary language was Hindi. Teachers' qualifications included a bachelor's or master's degree. The school intentionally split the students into two sections at each grade level on the basis of the students' achievement levels. Thus, one section contained low achievers and the other section contained high achievers.

The families of students in this school were predominantly extended families with relatives or grandparents living in the house. Only a few families were nuclear (20\%). Generally, men provided the primary source of income. Eighty percent of the parents were illiterate (i.e., less than primary education). The average family size was 3.5 children per family. The parent participation in the children's education was known to be minimal.

A second grade section of 46 low achieving students was selected for the intervention. Comparison data were collected from the other second grade section consisting of 48 students as well as the entire populations of first grade and third grade students in low and high achieving sections, respectively. There were more males than females in the second grade population (58\% males versus $42 \%$ females) but proportions were the same between the treatment and control groups.

We trained one second grade teacher and in two therapeutic breathing techniques (described in the intervention section). Once the teacher became comfortable using the techniques, she implemented them in the classroom. The experimental student group practiced the two breathing techniques for five minutes each, daily in the morning for the entire year under the guidance of this teacher. Academic performance data were collected on English, and math scores from the two groups at the start of the intervention and at the end of the intervention (called Unit 1 and Unit 2 tests, respectively). We also collected scores for the low and high achieving sections from the first and third grades.

To determine if the intact treatment and control groups were indeed low and high achievers in second grade before the intervention, we compared first grade end of year scores for the two groups. Prior to this examination, we determined that there were no outliers and that assumptions for parametric testing were not violated. The groups were statistically different on English $\left(M_{\text {breathing }}=59.87, M_{\text {control }}=79.08 ; t(70)=-6.289, p=\right.$ $0.000)$ and mathematics $\left(M_{\text {breathing }}=60.33, M_{\text {control }}=84.51 ; t(68)=-7.661, p=0.00\right)$ performances in first grade with the high achieving control group starting at a significantly higher level than the TBT group.

\subsection{Intervention Framework}

The two breathing techniques of deep breathing and alternate nostril breathing, respectively, were selected for the intervention. The reason for selection of the techniques was that they were effective in addressing the nervous system as addressed in the literature (Telles, et al, 2007), with no side-effects and easy to administer with young children. In the first breathing technique, the participant breathes in and out of the nose deeply. It is 
exactly like normal breathing, except there is deep inhalation and prolonged exhalation. In the second technique involving alternate nostril breathing, the participant inhales through one nostril and releases the breath through the other nostril and vice-versa in an alternating pattern. One can find a sample video of alternate-nostril breathing in the video clip at the URL:http://www.youtube.com/watch?v=MCK1jBfRVsE

At the outset of intervention, following the training, the teacher demonstrated the techniques to the subjects by using specific guidelines as described in Table 1. To ensure an accurate practice of the techniques, students practiced the two breathing techniques, first with the researchers and then independently. Breathing through the nose was emphasized during the entire process. The students kept their eyes open and preferred to use their fingers for counting during deep breathing. Given the young age of the children, alternate nostril breathing practice took a little more explanation and sometimes working with individual students. Initially, the students had a tendency to engage in unilateral breathing, i.e., repeated breathing in a single direction (e.g., just from the left nostril to the right nostril), but that was rectified via sufficient practice. One student preferred to switch hands, using right thumb for closing right nasal passage and left thumb for left one, which was acceptable. Once the techniques were attained, the students were asked to continue breathing in and out while counting, either mentally or with fingers, from one to five for each ingoing and outgoing breath over a fiveminute duration for each technique.

Table 1. Teacher's Narration for Breathing Techniques*

\begin{tabular}{|c|c|}
\hline Technique 1: Deep Breathing & Technique 2: Alternate Nostril Breathing \\
\hline $\begin{array}{l}\text { Relax, be comfortable and follow the directions. } \\
\text { Remember to breathe in and out through your nose. }\end{array}$ & $\begin{array}{l}\text { Relax, be comfortable and follow the directions. } \\
\text { Remember to breathe in and out through your nose. }\end{array}$ \\
\hline $\begin{array}{l}\text { Sit in upright position, with a straight back, keep your } \\
\text { back-bone upright, so that your head, neck and chest fall } \\
\text { in alignment in a straight line. }\end{array}$ & $\begin{array}{l}\text { Sit in upright position, with a straight back, keep your } \\
\text { back-bone upright, so that your head, neck and chest fall } \\
\text { in alignment in a straight line. }\end{array}$ \\
\hline $\begin{array}{l}\text { Let your hands rest on your lap. You may close your eyes } \\
\text { during this breathing exercise. }\end{array}$ & $\begin{array}{l}\text { Let your hands rest on your lap. You may close your eyes } \\
\text { during this breathing exercise. }\end{array}$ \\
\hline $\begin{array}{l}\text { Now take a deep, long breath in (counting mentally, or on } \\
\text { your fingers, from one to five as you breathe in). } \\
\text { When you finish counting, slowly start breathing out. And } \\
\text { as you breathe out, slowly release and let go of your breath } \\
\text { (counting mentally, or on your fingers, from one to five as } \\
\text { you breathe in). } \\
\text { While breathing, keep the focus on breath. } \\
\text { Repeat for } 3 \text { to } 5 \text { minutes until I say stop. }\end{array}$ & $\begin{array}{l}\text { Bring your right hand near your nose, put your right thumb } \\
\text { on the side of the right nostril and gently press the side of } \\
\text { the right nostril to close the right nasal passage. (The } \\
\text { position of the hand is like in 'preparing to 'pinch' nose } \\
\text { with thumb and index finger) } \\
\text { While keeping the right nasal passage closed, take a deep, } \\
\text { long breath in through the left nostril. } \\
\text { Now, let go of the right thumb. Press the side of the left } \\
\text { nostril gently to close the nasal passage with your fingers, } \\
\text { closing the left nostril breathe out from the right nostril. } \\
\text { Now, while keeping the left nostril closed, breathe in from } \\
\text { the right nostril. } \\
\text { Close the right nasal passage with the thumb and let go of } \\
\text { the fingers to open the left nostril and release your breath. } \\
\text { This completes one full round of alternate-nostril } \\
\text { breathing. } \\
\text { Switch sides and repeat the cycles. } \\
\text { While breathing, keep the focus on breath (or count to five } \\
\text { as you breathe in and count to five as you breathe out). } \\
\text { Repeat for } 3 \text { to } 5 \text { minutes. }\end{array}$ \\
\hline
\end{tabular}

* We strongly recommend that a student's physical health be taken into account before conducting breathing exercises and a physician be consulted for those with health issues. 
Initially, students had questions about the practice and some needed one-on-one guidance and demonstration. It took approximately one month to train the students. Sometimes, the teacher had to work oneon-one with a student to demonstrate the technique, especially in the case of alternate nostril breathing. Most common corrections in the technique related to slouching instead of sitting with an upright back, unilateral breathing (in single direction only, instead of alternate nostril breathing), twisting the nose with too much pressure instead of gently closing the nostril, or switching between fingers. Some students needed a tissue or a handkerchief due to mucus issues. The teacher supported the counting out loud to assist students with breathing and counting. After a few days of practice, the students became more comfortable with the technique.

To maintain fidelity in the implementation of the intervention, adherence to the dose of the intervention was measured by keeping a record of the practice. The frequency of practice was noted for the entire period of intervention. Equally important is the adherence to the content of the intervention. Teachers were trained to stick to the guidelines of the intervention by using the same directions across groups. The other critical component of implementation fidelity is the manner of delivery by different individuals. This element of fidelity was a limitation of the study, as there was less control on the disposition of teachers' attitudes or beliefs. As a partial means of minimizing the adverse effects of this limitation, the lack of significant perceived differences between the teachers' attitudes was confirmed with the school principal prior to the start of this study.

\subsection{Measures}

To determine academic differences in low achievers, who practiced TBT, and high achievers, we used unit tests in English and mathematics. The two subjects were selected because, in lower grades, schools traditionally focus on teaching knowledge and skills in these particular content areas. Additionally, academic achievement in English and mathematics was periodically measured via unit tests, which provided data for the study. The unit tests were administered at the beginning of the intervention (Unit 1) and at the end of the intervention (Unit 2). Tests were constructed by the school administration on the basis of government approved grade level curriculum. The tests were standardized within grade levels and were administered uniformly and concurrently across all sections within each grade. The test scores on each exam had a possible range of 0 to 100 points and each classroom teacher graded the tests on the basis of standardized expected responses. We calculated the gain scores by subtracting the pretest scores from the posttest scores (Unit 2 - Unit 1).

\subsection{Analytic Approach}

We used statistical techniques to compare groups. The first comparison was between low and high achieving first graders and their gain scores over a year's time. No students received TBT that year. The same students were then examined in second grade where low achievers received the TBT intervention but high achievers did not. Finally, we also examined the data for third graders who were split into low and high achieving groups and they had not received any $T B T$ intervention. This style of comparison mimics a regression discontinuity design.

To compare the low and high achieving groups, we utilized a type of general linear model called analysis of variance (ANOVA) with the additional factor of Gender (the groups had more males than females; gender was a significant predictor of achievement). Because of the focus on multiple comparisons (English, and mathematics), we used the Bonferroni alpha adjustment to conservatively guard against family-wise error.

\section{RESULTS}

The purpose of this study was to explore the potential relationship between TBT and academic performance, with an emphasis on low achieving students as compared to high achieving students. To do this, we asked:

To what extent do low and high achiever scores converge in English and mathematics after a $T B T$ intervention?

\subsection{English}

Perhaps the easiest way to discuss the results is to direct the reader to Figures 1(a) through 1(c), wherein we depict the differences between English scores of low and high achieving students in first, second, and third grades, respectively. The reader should note that the low and high achiever scores in each grade were different by a statistically significant margin at each point in time (i.e., grades 1, 2, and 3 at both Unit 1 and Unit 2 tests). Holding gender constant, high achievers outscored low achievers in English by at least 10 points. In the first and third grades, where NO therapeutic breathing exercises were practiced, the gulf between low and high achievers widened as the year progressed. High achievers made gains in the range of 4 to 6 points on average, 
while low achievers regressed about one point on average (Table 2). However, during second grade, when breathing exercises were practiced by low achievers, the low achievers made gains comparable to the high achievers. Both groups gained over two points on average. To be certain, the low achievers did not catch up with the high achievers, who had started well above the low achievers. Nor did the low achievers rise to a mean passing grade. But, the low achievers did make gains and did not 'fall back' (Alexander, Entwisle, Olson, 2007), thereby arresting the erstwhile trend of the "rich getting richer and poor getting poorer."

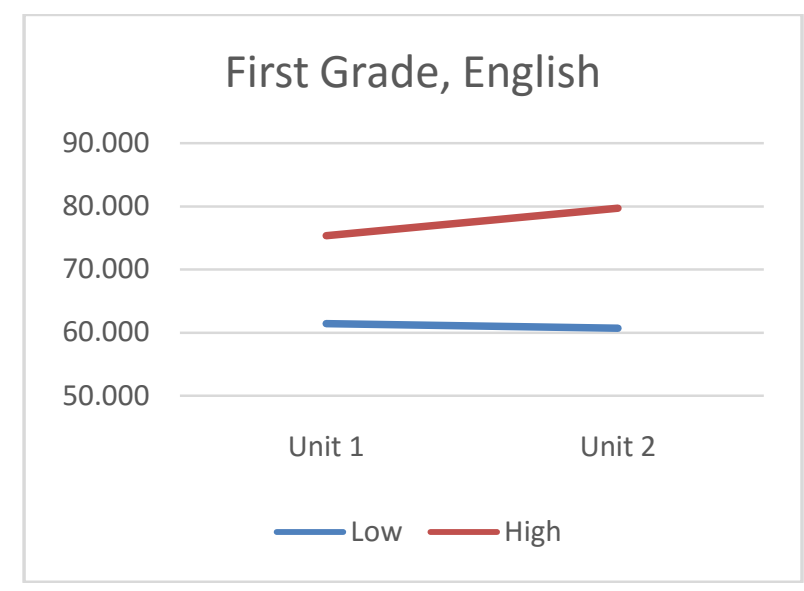

(a) First grade

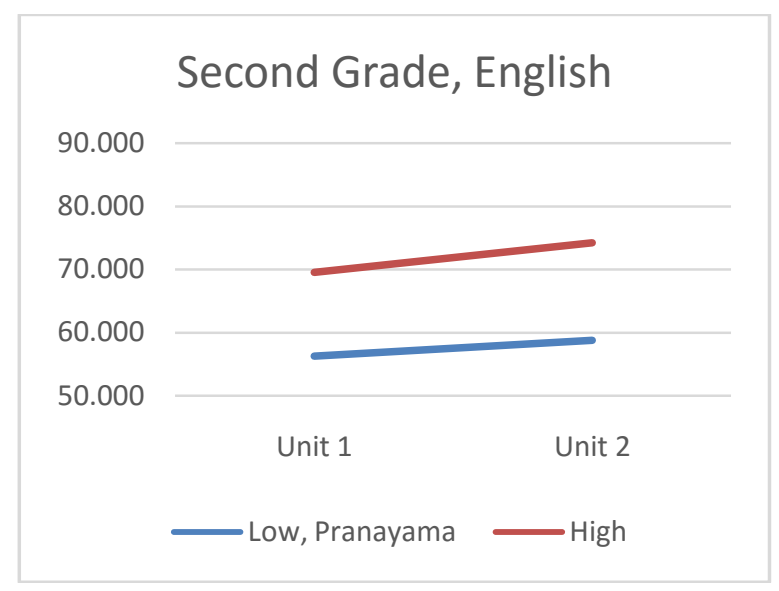

(b) Second grade

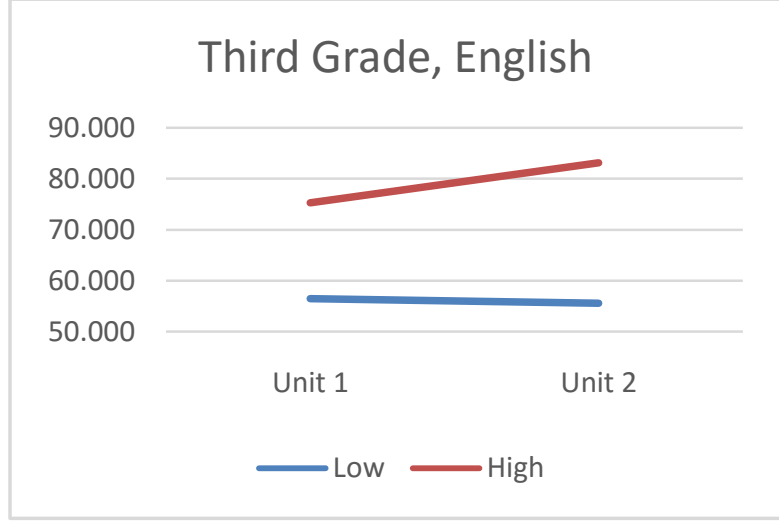

(c) Third grade

Figure 1. Trends in English scores for first, second, and third grades

Table 2.English gain scores for first, second and third graders.

\begin{tabular}{lcc}
\hline \hline & \multicolumn{2}{c}{ English } \\
\cline { 2 - 3 } & $\begin{array}{c}\text { Low Achievers } \\
\text { Average Gain }\end{array}$ & $\begin{array}{c}\text { High Achievers } \\
\text { Average Gain }\end{array}$ \\
\hline Grade 1 & -1.510 & 4.054 \\
Grade 2 TBT & 2.708 & 2.481 \\
Grade 3 & -1.009 & 6.585 \\
\hline
\end{tabular}

\subsection{Mathematics}

The results are similar for the mathematics scores. In Figures 2(a) through 2(c), we show the changes in the math scores of low and high achieving students in first, second, and third grades, respectively. Again, low and high achiever scores exhibited statistically significant differences at each point in time (grades 1, 2, and 3 at both Unit 1 and Unit 2 tests). High achievers started higher and significantly outscored low achievers in mathematics after controlling for gender. In the first and third grades, where NO TBT intervention was practiced, the gulf between low and high achievers widened as the year progressed. High achievers made gains of two to six points on average, while low achievers did the opposite, losing up to one point on average (Table $3)$. However, in second grade, when therapeutic breathing exercises were practiced by low achievers, the low 
achievers made gains that were actually greater than the high achievers. On average, low achievers gained five points in mathematics, whereas the high achievers only gained one point. Again, these gains are notable but they did not close the achievement gap created during previous year of lower academic performance. Nonetheless, the trend of increasing gaps in academic performance in time was reversed when the intervention was implemented.

Table 3.Mathematics gain scores for first, second and third graders.

\begin{tabular}{ccc}
\hline \hline & \multicolumn{2}{c}{ Mathematics } \\
\cline { 2 - 3 } & $\begin{array}{c}\text { Low Achievers } \\
\text { Average Gain }\end{array}$ & $\begin{array}{c}\text { High Achievers } \\
\text { Average Gain }\end{array}$ \\
\hline Grade 1 & -1.899 & 2.438 \\
Grade 2 TBT & 5.135 & 1.058 \\
Grade 3 & -0.539 & 6.473 \\
\hline
\end{tabular}

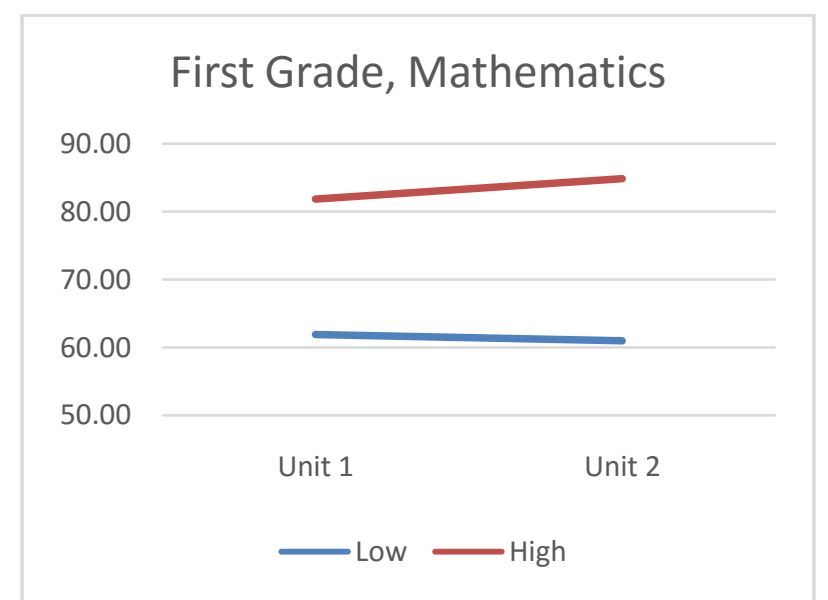

(a) First grade

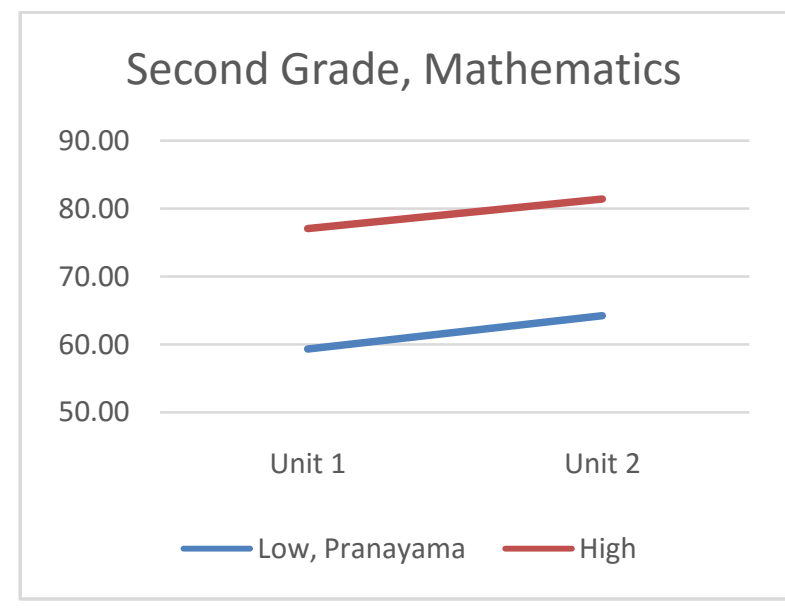

(b) Second grade

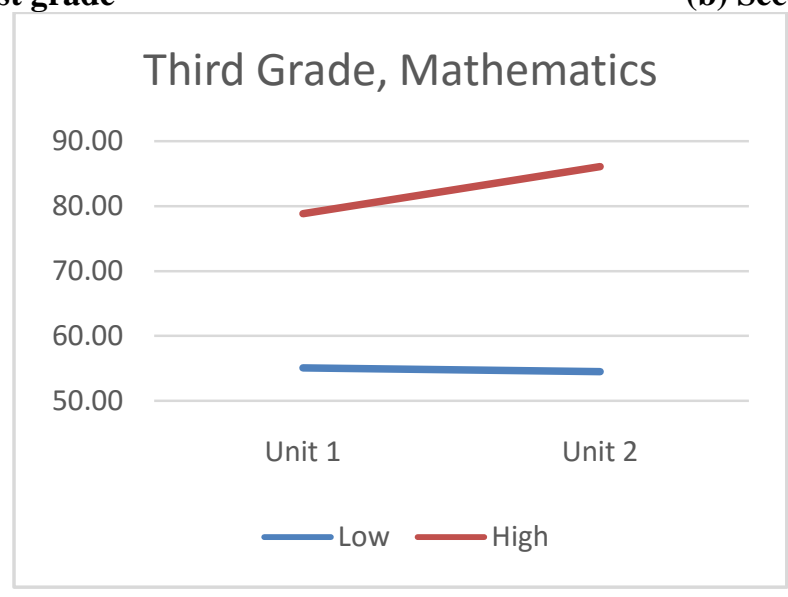

(c) Third grade

Figure 1. Trends in math scores for first, second, and third grades

\section{Discussion}

Yoga is a common practice throughout India with increasing popularity worldwide. Since breathing can be partially controlled and regulated, it is a useful tool. It requires no equipment and can be done anywhere. In the USA, the National Health Statistics Report indicates that $6 \%$ of children practice yoga (Barnes et al. 2008). Therapeutic breathing builds self-regulation, which is the ability to monitor and manage one's behavior, emotions, and thoughts. Yoga has been shown to be effective with behavior modification associated with test anxiety and mental stress (Telles, et al. 1994) as well as with promoting relaxation, greater self-awareness, selfcontrol, and concentration among children with a variety of physical diagnoses (Krusche, 1999). Schools have even seen behavior problems like bullying decrease with mindful interventions (Leland, 2015).Calm breathing is 
thought to help focus the mind and regulate the autonomic nervous system and, as a result, fosters relaxation (Steiner, 2013). Students perform better in relaxed state of mind and calm environment.

To our knowledge, the present study is the first of its kind to explore an alternative intervention through the use of therapeutic breathing exercises to improve academic performance in low achieving students. This study provides preliminary evidence for the feasibility and possible, modest effectiveness of TBT intervention in improving academic performance. These results contribute to the literature on improving children's performance in an academic setting. Assuming that the results of this study are replicated, TBT could become a promising alternative or complement to behavioral and academic interventions. The intervention has the potential to be implemented not only in small groups with targeted population but also with an entire classroom or across grade-levels. Cost concern is a legitimate issue for learning environments with low budgets in a tight economy. In an era of dwindling funding for schools, introducing new intervention is seldom an easy undertaking. However, teacher training cost associated with the intervention is minimal because of training videos that are freely available online. Student training in TBT is similarly inexpensive and relatively straightforward. There are many online audio-visual and interactive applications, software, and free downloads available for iPhones, iTunes (TBT Universal Breathing), and Android devices that can individualized to varying breathing paces.

Considering budgetary and other pragmatic considerations, TBT intervention could possibly provide a cost-effective and minimally invasive approach to improving student performance, particularly in developing countries with economic concerns. A more realistic concern than the monetary expenses associated with the intervention is the time it will take from learning activities and instructional tasks. Time spent during the intervention is ten to fifteen minutes and such short-duration practice of TBT can be easily incorporated into existing class schedules. With the current climate of accountability in schools, it is valuable for school entities to seek hard data to support their decisions to use or to discontinue specific interventions. Given the high stakes attached to the results, the time can be well spent as transitional activity time or as morning assembly time as in this study. Given adequate training and professional learning opportunities, teachers can lead the TBT practice in their classrooms at their convenience.

Based on the outcomes of this study, TBT intervention appears to have a small yet positive impact on academic performance in English and mathematics. Although the focus of our study was to examine the effects of intervention on academic outcomes, classroom teachers also reported observing improved behavior and selfcontrol in their students. There is dearth of research in this area, but the findings of this study are in concert with a few other studies for children with special needs that have indicated the benefits of yoga for that population (Peck et al., 2005). The study suggests that TBT-based interventions may have the potential to improve aspects of cognitive functioning associated with not only academics but also with self-regulation, including attention, self-control and focus. Enhancing regulatory behaviors may also have implications for ADHD and other at-risk students. The intervention has the potential to facilitate development of basic abilities that will promote a range of positive emotional, behavioral and academic outcomes. While our study is preliminary and the interpretation of the results of this study should be made with caution, it does provide some encouraging support for the potential efficacy of therapeutic breathing exercises on improved English and Math skills and test performance. In conclusion, the TBT merits further consideration as a potential means of assisting the students to relax and find that inner sanctum of stillness from which to regulate their behavior that is related to academic performance.

It is premature, however, to make any substantial conclusion regarding the generalization of these results to a larger population. Wider acceptance of yoga in the Indian context could have factored into the effects of the intervention. Students in the second grade treatment may have experienced a form of Hawthorne Effect in realizing that they were receiving TBT unlike their peers. Their parents may have discussed the intervention with the students during the consent process. Future studies could replicate the present effort with a larger numbers of students to investigate the effects of therapeutic breathing on additional outcome measures of reading, such as auditory discrimination, phonemic segmentation, and comprehension. Further research also needs to be done with a long-term follow-up to examine the sustainability of the effects of practicing TBT.

\section{RECOMMENDATIONS}

Additional studies involving larger student population would help shed further light on the possible connection between therapeutic breathing exercises and reduced disparity in academic performance. The present findings also suggest that further studies are warranted to determine the optimal duration and modality of therapeutic 
breathing exercises, as well as the sustainability of the intervention. The present study confined the treatment to the low achieving students. However, it is also worthwhile to conduct follow-on studies where the treatment group includes both low and high achievers and what impact that has on the academic performance of the high achieving students and also on the gaps between the performances of high achieving and low achieving students. Finally, this empirical study has focused on the measures of pre-existing unit tests in the schools. In future studies, measures of self-regulatory behaviors can be incorporated to help clarify the mechanism underlying the observed change. Empirical evidence indicates that students are not reliable estimators of their own behavior and cognitive activity (Veenman, 2006, Winne, Jamesion-Noel, 2002; Winne, 2006). Given the young age of students in this study, the use of self-reported data was a limitation. Therefore, future studies with older students in higher grades are encouraged to allow the incorporation of more reliable behaviour assessment tools.

\section{ACKNOWLEDGMENT}

This paper was prepared while the first author was a Visiting Scholar in the Graduate School of Education at Stanford University. Their hospitality during this period is gratefully acknowledged.

\section{REFERENCES}

[1] Alexander, Karl L., Entwisle, D., Olson, Linda, S. (2007). Lasting consequences of the summer learning gap. American Sociological Review, 72, 167-180.

[2] Barnes, P., Bloom, B., and Nahin, R. (2008) Complementary and alternative medicine use among adults and children: United States, 2007. National Health Statistics Reports, 12, 1-22.

[3] Berger, D. L., Silver, E.J., and Stein, R. (2009). Effects of yoga on inner-city children's wellbeing: A pilot study. Alternative Therapies in Health \& Medicine, 15 (5), 36-42.

[4] Black, S. (2005). Test anxiety. American School Board Journal, 192(6), 42-44.

[5] Brosnan, B. (1982). Yoga for handicapped people. London; Souvenir Press.

[6] Brown RP and Gerbarg PL, (2005).Sudarshan Kriya yogic breathing in the treatment of stress, anxiety, and depression: Part II-clinical applications and guidelines. J Alternative and Complementary Med. 11(4):711-717.

[7] Broderick, P., \& Jennings, P. (2012). Mindfulness for adolescents: A promising approach to supporting emotion regulation and preventing risky behavior. New Directions for Youth Development, 136, 111-126.

[8] Carlson, N. R. (1998). Physiology of behavior (6 ${ }^{\text {th }}$ ed.). Boston: Allyn and Bacon.

[9] Chatterjee, M. (2006).Reading achievement gaps, correlates, and moderators of early reading achievement: evidence from the early childhood longitudinal study (ECL) kindergarten to first grade sample. Journal of Educational Psychology, 98(3), 489-507.

[10] Clance, P. R., Mitchell, M., \&Engelman, S. R. (1980).Body cathexis in children as a function of awareness training and yoga. Journal of Clinical Child Psychology, 9, 82-85.

[11] Goldbeck, L. \& Schmid, K. (2003).Effectiveness of autogenic relaxation training on children and adolescents with behavioral and emotional problems. Journal of the American Academy of Child and Adolescent Psychiatry, 42, 1046-1054.

[12] Grossman, P., Niemann, L., Schmidt, S., \& Walach, H. (2004). Mindfulness-based stress reduction and health benefits. Journal of Psychosomatic Research, 57(1), 35-43.

[13] Gupta, A., Sinha, S., Pribesh, S., \& Maira S. (2014). Fresh breath into reading: impact of pranayama on reading skills and academic performance. International Journal of Humanities and Social Science Invention, 3(10), 38-46.

[14] Jencks, C. \& Phillips, M. (Eds.). (1998). The black-white test score gap. Washington, DC: Brookings Institution Press.

[15] Krusche, F. (1999). Yoga respiratory therapy helps children with asthma. Fortschritte der Medizin, 117, 44.

[16] Larson, Heidi, A., El Ramahi, Mera K., Conn, Steven R. (2010). Reducing Test Anxiety among Third Grade Students through the Implementation of Relaxation Tecnhiques. Journal of School Counseling, 8(19).

[17] Lalvani, V.(1999). Classic yoga for stress relief. New York: Sterling Publishing Co. Inc.

[18] Leland, Matt. (2015). Mindfulness and Student Success. Journal of Adult Education, 44(1), 19-24.

[19] Napper-Owen, Gloria. (2006). Meditation and Relaxation Awareness. Teaching Elementary Physical Education, 17(1), 18-19.

[20] Nardo, A.C. \& Reynolds, C. (2002). Social, emotional, behavioral, and cognitive benefits of yoga for children: A non-traditional role for school psychologists to consider. Paper presented at the annual meeting of the National Association of School Psychologists, Chicago. IL.

[21] Peck, H.L., Kehle, T.J., Bray, M.A., \& Theodore, L.A. (2005).Yoga as an intervention for children with attention problems. School Psychology Review, 34, 415-424.

[22] Seamon, J.G. \& Kenrick. D.T. (1994). Psychology. New, Jersey: Prentice Hall.

[23] Spielberger, C.D., \& Vagg, P.R. (1995). Test Anxiety: Theory, assessment, and treatment. Washington D. C.: Taylor \& Francis.

[24] Steiner, N., Sidhu, T., Pop, P., Frenette, E., \& Perrin, E. (2013). Yoga in an Urban School for Children with Emotional and Behavioral Disorders: A Feasibility Study. Journal Of Child \& Family Studies, 22(6), 815-826. 
[25] Stueck, M., Gloeckner, N., (2005). Yoga for children in the mirror of the science: working spectrum and practice fields of the training of relaxation with elements of yoga for children. Early Child Development and Care, 175(4), 371-377.

[26] Telles, S.,Hanumanthaiah, B. H., Nagarathna, R., Nagendra, H. R. (1994). Plasticity of motor control systems demonstrated by yoga training of school children.Perceptual and Motor Skills, 104, 1264-1266.

[27] Telles, S., Raghuraj, P., Maharana, S., Nagendra, H.R. (2007). Immediate effect of three yoga breathing techniques on performance on a letter-cancellation task.Perceptual and Motor Skills, 104, 1289-1296.

[28] Veenman, M. V. J., Van Hout-Wolters, B. H. A. M., \& Afflerbach, P. (2006). Metacognition and learning: conceptual and methodological considerations. Metacognition and Learning, 1, 3-14.

[29] Williamson, Lisa Ann. (2012). Yoga in Public Schools. Teaching Tolerance, 42, 27-28.

[30] White, L.S. (2009). Yoga for children. Pediatric Nursing, 35(5) 277-295.

[31] Willis, Elizabeth, D., Laura H. (2014). Contemplative practices in early childhood: Implications for self-regulation skills and school readiness. Early Child Development Care, 184(4), 487-499.

[32] Winne, P. H., \& Jamieson-Noel, D. (2002). Exploring students' calibration of self-reports about study tactics and achievement. Contemporary Educational Psychology, 27, 551-572.

[33] Winne, P. H., Nesbit, J. C., Kumar, V., Hadwin, A. F., Lajoie, S. P., Azevedo, R., et al.(2006). Supporting selfregulated learning with gStudy software: The learning kitproject. Technology, Instruction, Cognition and Learning, 3, 105-113. 